\title{
LA RECEPCIÓN DEL LÉXICO ESPECIALIZADO EN LA NOVENA (1843) Y DÉCIMA (1852) EDICIONES DEL DRAE
}

\section{THE RECEPTION OF SPECIALIZED WORDS IN THE NINTH (1843) AND TENTH (1852) EDITIONS OF THE DRAE}

\author{
Laura Muñoz Armijo \\ Universitat Autònoma de Barcelona \\ Grupo de Lexicografía y Diacronía \\ Laura.Munoz@uab.cat
}

Recibido: $14 / 01 / 2019$

Aceptado: 15/04/2019

\begin{abstract}
Resumen
En las ediciones centrales del siglo XIX surge una polémica intelectual con respecto a la admisión del léxico especializado. Los prólogos de la novena (1843) y décima (1852) ediciones dan cuenta de las tensiones en el seno de la Corporación por los ataques de los autores de la lexicografía no académica. El propósito de la presente investigación es caracterizar la admisión del léxico especializado en las dos ediciones de mediados del siglo XIX. Para ello, y en primer lugar, se partirá de la información sobre el léxico de especialidad que contienen los prólogos y las Reglas de 1838; en segundo lugar, se analizarán los lemas marcados y no marcados de ambas ediciones académicas. Finalmente, se tratará de determinar las posibles influencias que algunos diccionarios no académicos (principalmente las obras de Terreros (1786-1793), Núñez de Taboada (1825), Salvá (1846)) pudieron ejercer en la admisión de voces de especialidad en la novena y décima ediciones.
\end{abstract}

\begin{abstract}
In the central editions of the nineteenth century, an intellectual polemic arises with respect to the admission of the specialized lexicon. The prologues of the ninth (1843) and tenth (1852) editions give an account of the tensions within the Corporation due to the attacks of the authors of non-academic lexicography. The purpose of this research is to characterize the admission of the specialized lexicon in the two editions of the mid-nineteenth century. For this, and in the first place, it will be based on the information on the lexicon of specialty contained in the prologues and the Reglas of 1838; secondly, the marked and unmarked slogans of both academic editions will be analyzed. Finally, it will try to determine the possible influences that the non-academic dictionaries of the first half of the nineteenth century could exercise in the admission of specialty voices in the ninth and tenth editions.
\end{abstract}

Para citar este artículo / To cite this article: Muñoz, Laura (2019). La recepción del léxico especializado en la novena (1843) y décima (1852) ediciones del DRAE. Azorín, Dolores; Clavería, Gloria y Jiménez Ríos, Enrique (Eds.): ELUA: El diccionario de la Academia y su tiempo: lexicografía, lengua y sociedad en la primera mitad del siglo XIX, Anexo V, págs. 315-338.

Enlace/Link: http://dx.doi.org/10.14198/ELUA2019.ANEXO5.13

(c) BY-NC Este trabajo se publica bajo una licencia de Creative Commons Reconocimiento-NoComercial 4.0 Internacional 
PALABRAS CLAVE: Lexicografía académica, léxico especializado, S. XIX, DRAE 1843, DRAE 1852
KEY WORDS: Academic Lexicography, Specialized Words, 19th c, DRAE 1843, DRAE 1852

\section{INTRODUCCIÓN}

El siglo XIX representa para la historia de la lexicografía española un importante desarrollo de la técnica lexicográfica y su posterior consolidación especialmente en las últimas décadas. En estos años se sientan las bases de la estructura que presentan los diccionarios actuales. Todo ello viene propiciado por la sucesión de una serie de acontecimientos históricos, como el nacimiento de nuevas teorías científicas y sociales o los avances tecnológicos, que irrumpen en la sociedad española contemporánea.

Una consecuencia directa del conjunto de estas innovaciones es el significativo crecimiento del léxico científico y técnico que se ve reflejado en la nomenclatura de los repertorios lexicográficos académicos ${ }^{1}$ y no académicos ${ }^{2}$; estos últimos desde la primera mitad del siglo XIX "disputan a la Corporación el monopolio que venía disfrutando en el terreno de la lexicografía monolingüe castellana" (Azorín 2000: 229). Las críticas de lexicógrafos como Núñez de Taboada, Peñalver o Salvá, ante el escaso repertorio de voces técnicas en las ediciones del DRAE, generan un intenso debate acerca de los criterios de admisión de los neologismos y extranjerismos, desde una perspectiva general, y del léxico de especialidad, desde una perspectiva particular, en el seno de la Real Academia Española ${ }^{3}$ cuyas reflexiones han quedado testimoniadas en las actas de las sesiones académicas (Clavería y Freixas 2015, Freixas 2019), en los prólogos de las ediciones académicas (de especial relieve, esta cuestión se menciona en el prólogo de la novena edición) y en la publicación de las Reglas para la corrección y aumento del diccionario de 1838. La existencia de estos documentos proporciona al investigador una valiosa fuente de información sobre el procedimiento de elaboración en cada una de las ediciones del diccionario y sobre la concepción del léxico de especialidad, tema central del presente estudio.

La presente contribución tiene como objetivo examinar la admisión y el tratamiento del léxico especializado en las ediciones centrales del siglo XIX, novena de 1843 y décima de 1852, en el contexto de polémica intelectual descrito anteriormente. Con tal finalidad, se recurrirá, por un lado, a la información contenida en las Reglas de 1838 y al Prólogo del Diccionario de ambas ediciones y, por otro, al examen de las entradas lexicográficas que se añaden respecto a las ediciones anteriores de 1837 (para la novena edición) y 1843 (para la décima edición $)^{4}$. Finalmente, un propósito complementario derivado del anterior se ciñe

1 Véanse Clavería/Freixas (2018) sobre el DRAE 1817, Terrón (2019) sobre el DRAE 1822 y Carriet (2017) sobre el DRAE 1832.

2 Vid. las investigaciones sobre los diccionarios no académicos de la primera mitad siglo XIX: Seco 1987; Baquero Mesa 1992; Azorín 1996, 2000, 2002; García Platero 2003; Muñoz 2007; Raab 2018.

3 Vid. Clavería 2007, 2010, 2016; Esparza Torres 1999; Freixas 2019; Muñoz 2007.

4 En este trabajo se parte de la metodología de análisis establecida en el proyecto de investigación "Historia interna del Diccionario de la lengua castellana de la Real Academia Española en el siglo XIX (1817-1852)", dirigido por Gloria Clavería (núm. de referencia FFI2014-51904-P), cuya financiación, junto al apoyo de la Generalitat de Catalunya para el Grupo de Investigación Consolidado "Grup de Lexicografia i Diacronia" (núm. de referencia 2017 SGR 1251), ha hecho posible las investigaciones realizadas para su consecución. Se ha contado con los datos sobre el aumento de voces, recogidos a través de la herramienta de búsqueda de $1 .{ }^{\mathrm{a}}$ doc. del NTLLE, disponibles en http://docs.wixstatic.com/ugd/c44fb6_55bb849d665f43d3ac15e3b2f0c0bc66.pdf. 
al análisis de las influencias que la lexicografía académica haya podido recibir de las obras no académicas que podrían explicar el cambio de orientación con respecto a los criterios de admisión del léxico de especialidad que la Corporación parece protagonizar a partir de la novena edición. Para ello, se han seleccionado los repertorios de Terreros (1786-1793), Núñez de Taboada (1825) y Salvá $(1846)^{5}$ mediante los que se realizará un cotejo con las primeras documentaciones de lemas con alguna abreviatura diatécnica en la novena y, especialmente, en la décima edición del $D R A E$.

\section{LA INFORMACIÓN ESPECIALIZADA EN LA NOVENA Y LA DÉCIMA EDI- CIONES DEL DRAE}

$\mathrm{Al}$ adentrarnos en la caracterización del léxico especializado en las ediciones del $D R A E$ de mediados del siglo XIX previamente resulta imprescindible aludir a un problema teórico tratado en la bibliografía: las dificultades de delimitación entre el léxico general de la lengua común y el léxico específico que procede de diferentes ámbitos de especialidad. Esta cuestión se ha tratado ampliamente en numerosas monografías (Azorín 1992, Cabré 1992, Martín Zorraquino 1997, Gutiérrez Rodilla 1998) y recientemente en indagaciones aplicadas al léxico especializado en la lexicografía académica española (Carriazo y Gómez 2010, Torruella y Huertas 2018, Gómez de Enterría 2018).

La información procedente de los prólogos desde el Diccionario de autoridades hasta la octava edición (1837) señala un criterio conservador de la Academia con respecto a la inclusión de voces especializadas que no formen parte del léxico común, como se justifica ampliamente en Torruella y Huertas (2018: 253-255). La Corporación sigue fiel a sus criterios más tradicionales, como se venía haciendo desde Autoridades, de documentar sus voces en autores prestigiosos de tratados de diferentes ámbitos de especialidad. En particular, como se ha señalado en Freixas (2019), en los prólogos de 1843 y 1852 se aplica como método lexicográfico el principio descrito en las "Adiciones" a las Reglas de 1838: "las autoridades de voces facultativas se tomarán de los mejores autores del arte o facultad respectiva, como para las de mineralogía y metalurgia de Vargas en su tratado de Re metálica" (Reglas 1838: 28). Con esta arma defensiva la Corporación se justifica en el prólogo de la novena edición (1843) ante las reiteradas acusaciones que recibe a lo largo de la primera mitad del siglo XIX (Jiménez Ríos 2013, Clavería 2016). Así, la siguiente explicación del prólogo de 1843 justifica la rigurosidad de la Academia en la selección del léxico y en su documentación:

Hay sin embargo en el lenguaje social voces de uso corriente, que por designar objetos frívolos, transitorios y casi siempre de origen y estructura extranjera no deben tener entrada en el Diccionario de una lengua, y si bien no faltan en el nuestro vocablos de esta clase pertenecientes á tiempos pasados, la Academia está persuadida de que no deben admitirse. Tales son los que se refieren á objetos de modas pasajeras y fugaces, como canesús, bandolina, capotas y otros á este tenor que nacen hoy y mueren mañana sin

5 La elección de los diccionarios mencionados y no otros, como el de Labernia (1844) o Domínguez (1853), se justifica por la selección de algunos de los repertorios más representativos de finales del siglo XVIII y de la primera mitad del siglo XIX. En estudios anteriores (Muñoz 2007, 2012) se ha destacado la significativa contribución que los tres diccionarios no académicos escogidos aportan en el método de adición y enmienda a lo largo de las ediciones del DRAE del siglo XIX. 
dejar mas vestigios que la burla que de ellos suele hacer para diversion del público algun festivo escritor satirico ó dramático (DRAE 1843: Prólogo).

En el prólogo “Al lector” de la décima edición (1852), se explicita el interés por la selección del léxico de especialidad en consonancia con la evolución de la sociedad del momento y dando respuesta con adición de lemas del ámbito de la industria, la administración pública y del comercio:

(...) sin variar el plan de la obra ha procurado mejorarla; no solo enriqueciéndola con muchas voces y locuciones que, ó desde antes le faltaban, ó modernamente introducidas se han generalizado en el uso, sino quitando á varias la inmerecida nota de anticuadas (...). El mayor número de vocablos ahora agregados procede, ya de las novedades que se han ido experimentando en todos los ramos de la administración pública por consecuencia de actuales instituciones políticas, ya del rápido vuelo que á su sombra tutelar han tomado las artes, el comercio y la industria (DRAE 1852: Al lector).

De las reflexiones anteriores contenidas en los prólogos sobre la metodología usada en la elaboración del Diccionario y, en especial, para el tratamiento del léxico especializado se desprende una perspectiva pragmática, esto es "del uso lingüístico" (Azorín 1992: 447) en las ediciones de 1843 y 1852 . En este sentido, nuestra interpretación de la visión del léxico especializado en las dos ediciones estudiadas coincide con la interpretación de Torruella y Huertas (2018: 255) para el análisis de la edición de 1817:

En nuestra opinión, el DRAE 1817 tiene un carácter pragmático más que nocional, puesto que las palabras se marcan como pertenecientes a un campo de especialidad no según su área temática correspondiente, sino según su nivel de especialidad, es decir, según si la palabra es privativa de los especialistas o si es ampliamente conocida.

Además de la diferenciación entre léxico general y léxico especializado, los lemas que pertenecen a este segundo grupo se caracterizan por no estar marcados en su totalidad con una abreviatura diatécnica. Por ejemplo, muchos neologismos no van acompañados de marca: ello se ha podido constatar en la monografía sobre los lemas en -ismo e -ista en los DRAE (siglos XVIII-XX) (vid. Muñoz (2012)): absolutismo, articulista, ascetismo, cesionista, clasicismo (DRAE 1843), federalismo, optimismo, optimista, prosaísmo, protestantismo, romanticismo (DRAE 1852).

Con respecto al grupo de lemas marcados, la Academia parece mantenerse fiel a abreviaturas que presentan una amplia tradición en su diccionario: "la náutica es un área tradicionalmente privilegiada en la lexicografía académica (Azorín 2000; Carriazo 2015) y, como tal, presenta el mayor número de nuevas incorporaciones con marca; le siguen las disciplinas médicas — medicina, anatomía y cirugía - y las ciencias naturales — botánica, minería e historia natural_." (Torruella y Huertas 2018: 270).

\subsection{Las abreviaturas de especialidad del $D R A E 1843$ y $D R A E 1852$}

Las listas de abreviaturas de los prólogos de las dos ediciones centrales del siglo XIX presentan el mismo número de abreviaturas diatécnicas, 73 en total, que se mantienen inalterables desde la sexta edición de 1832. Reconstruyendo la historia de las ediciones 
académicas: “el $D R A E 1780$ recogía 68 marcas, el $D R A E 1803$ contenía 71, mientras que el $D R A E 1817$ presenta de nuevo 68" (Torruella y Huertas 2018: 259). Las 73 marcas de las ediciones de 1832, 1837, 1843, 1852 y 1869 se amplían en el DRAE 1884 que cuenta con 77 marcas (se añaden Agrim., Arqueol., Astrol., Bibliogr., Equit., Fisiol., Geod., Geol., Hidrául., Hidrom., Hig., Metal., Mineral., Numism., Obst., Taurom., Teol., Tint., Topogr., Trig., Veter. y Zool. y se suprimen Alfar., Anat., Ball. o Ballest., Cabestr., Cer., Cerraj., Coc., Dog., Dram. o Dr., Jin., Man. o Maniq., Opt., Orat., Plat., Polit. y Sastr. ) y en el DRAE 1899, que recoge un total de 82 marcas, se añaden Fotogr., Ling., Mec., Meteo. y Métr. En las dos últimas ediciones del siglo XIX tienen lugar significativos cambios, entre ellos la supresión de marcas menos representativas en el uso de la lengua, que responden a la evolución de los cambios sociales y avances tecnológicos de la época. En este sentido, las enmiendas realizadas en las marcas diatécnicas evidencian una perspectiva de uso lingüístico de carácter pragmático (Azorín 1992: 447) en la concepción del léxico de especialidad, aspecto comentado anteriormente (vid. § 2) en el que el contexto social ejerce una significativa influencia como sostiene Battaner (1996: 101):

el ámbito de lo especializado es algo que va cambiando con el tiempo y que la Academia determina siguiendo la organización onomasiológica de las ciencias, las artes y la técnica, en sus versiones teóricas, aplicadas y profesionales. El concepto voz / acepción especializada está supeditado a cambios históricos de valoración.

Por lo que respecta a la distribución de marcas diatécnicas que acompañan a las voces incorporadas en las dos ediciones, en la novena edición de 1843 se incluyen 49 lemas marcados con alguna abreviatura diatécnica (vid. Tabla 1), mientras que en la edición siguiente de 1852 se adicionan 65 lemas de algún ámbito especializado (vid. Tabla 2). En la novena edición constan 22 marcas diatécnicas diferentes y este mismo número se mantiene en la edición siguiente. La representación de cada de las marcas diatécnicas de ambas ediciones se ha sistematizado en las tablas 1 y 2 :

\begin{tabular}{|c|c|c|}
\hline $\begin{array}{l}\text { Marcas } \\
\text { diatécnicas }^{6}\end{array}$ & $\begin{array}{c}\mathrm{N} .^{\circ} \\
\text { acepciones }\end{array}$ & Lemas \\
\hline Astr. & 3 & aberracion, culminante, deviacion \\
\hline anat. /Anat. & 2 & lumbar, vertebrado \\
\hline Arq. & 1 & entramar \\
\hline Blas. & 1 & tortillos \\
\hline Bot. & 1 & liquen \\
\hline Carp. & 1 & borriquete \\
\hline Cir. & 1 & traqueotomía \\
\hline Esc. & 1 & torso \\
\hline
\end{tabular}

6 En el formato de las abreviaturas de las tablas se ha trasladado exactamente la ortotipografía de estas en las ediciones del DRAE. 


\begin{tabular}{|c|c|c|}
\hline $\begin{array}{l}\text { Marcas } \\
\text { diatécnicas }\end{array}$ & $\begin{array}{c}\mathrm{N} .^{0} \\
\text { acepciones }\end{array}$ & Lemas \\
\hline for. & 9 & $\begin{array}{l}\text { condómino, espontanearse, excarceracion, incautarse, } \\
\text { indagatorio, infringir, interdicto, premoriente, refeccionario }\end{array}$ \\
\hline Fort. & 2 & aspillera, parapetarse \\
\hline Geog. & 1 & orientar \\
\hline Geom. & 1 & exaedro \\
\hline Gram. & 1 & elision \\
\hline Hist. nat. & 3 & estalactita, mandril, portaalmizcle \\
\hline Impr. & 1 & entredos \\
\hline leg. & 1 & iniciativa \\
\hline Med. / med. & 7 & $\begin{array}{l}\text { amáurosis, asfixia, deletéreo, deviacion, gástrico, mucosidad, } \\
\text { protuberancia }\end{array}$ \\
\hline Milic. / Mil. & 5 & carronada, desfile, dispersar, escalafon, pontonero \\
\hline Mús. & 1 & arpegio \\
\hline Náut. & 3 & escuna, orientar, troceo \\
\hline Pint. / Pint. & 2 & amaneramiento, esfumino \\
\hline Ret. & 1 & etopeya \\
\hline
\end{tabular}

Tabla 1. Lemas con marcas diatécnicas en la novena edición de DRAE (1843). [Datos extraídos de Freixas 2019].

\begin{tabular}{|l|c|l|}
\hline \multicolumn{1}{|c|}{ Marcas diatécnicas } & N. $^{{ }^{0} \text { acepciones }}$ & \multicolumn{1}{|c|}{ Lemas } \\
\hline Agric. & 1 & vertedera \\
\hline Anat. & 3 & $\begin{array}{l}\text { crispar } \\
\text { pélvis } \\
\text { yeyuno }\end{array}$ \\
\hline Arq. & 1 & $\begin{array}{l}\text { churrigueresco } \\
\text { labra } \\
\text { salmer (reintroducción) }\end{array}$ \\
\hline Bot. & 4 & $\begin{array}{l}\text { infareda } \\
\text { ritotomía } \\
\text { litotricia } \\
\text { odontalgia }\end{array}$ \\
\hline Cir. & 4 & $\begin{array}{l}\text { comandita (en) } \\
\text { cotizar } \\
\text { cupon } \\
\text { gerencia }\end{array}$ \\
\hline Com. & & \\
\hline
\end{tabular}




\begin{tabular}{|c|c|c|}
\hline Marcas diatécnicas & N. ${ }^{\circ}$ acepciones & Lemas \\
\hline Farm. & 2 & $\begin{array}{l}\text { demulcente } \\
\text { manipulacion }\end{array}$ \\
\hline For. & 5 & $\begin{array}{l}\text { bastanteo } \\
\text { condominio } \\
\text { obtentor } \\
\text { ponencia } \\
\text { probatoria }\end{array}$ \\
\hline Geom. & 4 & $\begin{array}{l}\text { dodecaedro } \\
\text { duodecágono } \\
\text { icosaedro (reintroducción) } \\
\text { romboidal }\end{array}$ \\
\hline Gram. & 2 & $\begin{array}{l}\text { apódosis } \\
\text { prepositivos }\end{array}$ \\
\hline Hidrogr. & 1 & portulano \\
\hline Hist. nat & & estalacmita \\
\hline Impr. & 2 & $\begin{array}{l}\text { maculatura } \\
\text { versalita }\end{array}$ \\
\hline Mat. & 2 & $\begin{array}{l}\text { infinitesimal } \\
\text { polinomio }\end{array}$ \\
\hline Med. & 7 & $\begin{array}{l}\text { afta } \\
\text { carnificación } \\
\text { emuntorio } \\
\text { hidropatía }(1852 \mathrm{~S}) \\
\text { homeopatía }(1852 \mathrm{~S}) \\
\text { profiláctica } \\
\text { tétanos }\end{array}$ \\
\hline Milic. / Mil. & 2 & $\begin{array}{l}\text { racionar } \\
\text { vivaque (reintroducción) }\end{array}$ \\
\hline Min. & 1 & sílice \\
\hline Náut. & 7 & $\begin{array}{l}\text { descalcador } \\
\text { descalcar } \\
\text { descalimar } \\
\text { farola }\left(2^{\mathrm{a}} \mathrm{acep}\right) \\
\text { muz } \\
\text { toar } \\
\text { trincadura }\end{array}$ \\
\hline Pint. & 2 & $\begin{array}{l}\text { amanerarse } \\
\text { lontananza }\end{array}$ \\
\hline Poét. & 5 & $\begin{array}{l}\text { astur } \\
\text { ponto } \\
\text { procela } \\
\text { rielar } \\
\text { rigente }\end{array}$ \\
\hline
\end{tabular}




\begin{tabular}{|l|c|l|}
\hline \multicolumn{1}{|c|}{ Marcas diatécnicas } & $\mathbf{N}^{{ }^{0}}$ acepciones & \multicolumn{1}{c|}{ Lemas } \\
\hline Quím. & 6 & $\begin{array}{l}\text { acetato (1852 S) } \\
\text { acético (1852 S) } \\
\text { carbonato } \\
\text { cloro } \\
\text { nitrato } \\
\text { sulfato (1852 S) }\end{array}$ \\
& & \\
\end{tabular}

Tabla 2. Lemas con marcas diatécnicas en la décima edición de DRAE (1852).

Si se contrastan los datos procedentes de las dos tablas anteriores, se observa, en primer lugar, un predominio de acepciones marcadas en ámbitos tradicionalmente representados desde el Diccionario de autoridades: como el ámbito forense (9 acepciones nuevas en 1843 y 5 en 1852); el de la náutica (3 en 1843) que se duplica en la edición de 1852 con 7 acepciones marcadas; el médico, que mantiene la misma representación de acepciones marcadas en ambas ediciones (7 acepciones). En menor medida, la historia natural, ampliamente registrada desde ediciones académicas anteriores, presenta un menor protagonismo en ambas ediciones, así como otras áreas como la milicia (5 acepciones en 1843 y 2 acepciones en 1852), la arquitectura ( 1 acepción en 1843 y 3 acepciones en 1852) o la anatomía ( 2 acepciones en 1843 y 3 acepciones en 1852). Esta es una de las conclusiones que sostiene Freixas en su indagación sobre el aumento de la voces en la novena edición del DRAE (1843): “asimismo, se observa cómo las marcas se reservan para ámbitos tradicionalmente muy representados en el $D R A E$, mientras que otras áreas muy presentes en el aumento de la novena edición, como las voces de la política o de la retórica, no reciben marcas” (Freixas 2019).

En segundo lugar, destaca el aumento de voces especializadas de ámbitos científicos que experimentan significativos avances a lo largo del siglo XIX: cirugía (4 acepciones), geometría (4 acepciones), matemáticas ( 2 acepciones), farmacia (2 acepciones). Especialmente, es notable el crecimiento del ámbito de la química al que pertenecen 6 acepciones que corresponden a nombres de sales (acetato, acético carbonato, nitrato, sulfato) y elementos químicos (cloro). Junto a los ámbitos anteriores, son destacables las acepciones del comercio (4 acepciones) y la poética (5 acepciones). La adición de voces especializadas de los ámbitos mencionados responde a la intención señalada en el prólogo de la décima edición (1852): "ya del rápido vuelo que á su sombra tutelar han tomado las artes, el comercio y la industria" (DRAE 1852: Al lector).

Finalmente, la abreviatura "Hidrogr" con la que se marca el lema portulano no aparece en la lista de abreviaturas de la décima edición y tampoco en ediciones posteriores:

PORTULANO. m. Hidrogr. Colección de planos de varios puertos, encuadernada en forma de atlas (DRAE 1852).

El ámbito de la hidrografía se define en la 23. a edición del $D R A E$ (2014) como la "parte de la geografía física que trata de la descripción de las aguas del globo terrestre", en su primera acepción, y como el "conjunto de las aguas de un país o región", en su segunda acepción. Probablemente, en un primer momento se decidió marcar la voz y, al no estar presente la marca "Hidrogr." en la lista de abreviaturas, se decidió suprimir dicha marca en la edición siguiente y así es como se ha mantenido hasta la 23. a edición (2014). 


\subsection{Procedimientos de indicación de especialidad}

Un atento examen de las definiciones del corpus de la presente investigación permite postular que en la novena y décima ediciones académicas se encuentra una manera de proceder muy similar a la señalada por Torruella y Huertas para la quinta edición de 1817:

así pues, en la edición de 1817 y para indicar el campo de especialidad, se utiliza el sistema de abreviaturas establecido desde 1780, pero se conservan muchas voces que continúan utilizando la forma de proceder de Autoridades, consistente en hacer referencia al ámbito dentro de la definición [...] En el fondo, parece que subyace la idea que la Academia concretó en las Reglas de 1869, en las que se detalla que "se omitirá la indicación de la ciencia, arte ú oficio, á que pertenece la voz técnica, por cuanto tal circunstancia se deduce fácilmente de la misma definición" (Reglas, 1869: 2) (Torruella y Huertas 2018: 267-268).

De este modo, en las voces de especialidad dicha condición se puede indicar mediante tres procedimientos distintos ${ }^{7}$. Por un lado, la marca diatécnica consta tras el lema o al inicio de la acepción:

ACETATO. m. Quím. La sal que proviene de la combinación del ácido acético ó de vinagre con diferentes sustancias (DRAE 1852S: s.v. acetato $)^{8}$.

Este modo de proceder, según las tablas 1 y 2 anteriores, se ha localizado en 49 lemas en la novena edición de 1843 y en 65 lemas en la edición siguiente de 1852. Teniendo en cuenta el número total de introducciones en ambas ediciones (vid. § 3), la proporción de voces marcadas representa una parte poco representativa del léxico. De esta manera, en la práctica lexicográfica la marcación de voces no es el método más recurrente.

Por otro lado, en numerosos casos los lemas o acepciones aparecen sin marca diatécnica pero esta información se detalla en la redacción de la definición con contornos especificadores del ámbito especializado:

CÁNULA. f. Cañoncito que se emplea en varios usos. Es voz muy usada en cirujía. (DRAE 1852S).

Finalmente, la acepción especializada puede deducirse por la relación de semejanza con otras voces de la misma familia que aparecen marcadas. Por ejemplo, el verbo cotizar dispone de la marca diatécnica "Com." (Comercio) pero, en cambio, el sustantivo cotización no conserva esta marca pero en su definición se remite a él. Lo mismo ocurre en los lemas comanditario y comandita (en):

COTIZAR. a. Com. Publicar en alta voz en la bolsa el precio de los documentos de la deuda del Estado, ó de las acciones mercantiles que tienen curso público (DRAE 1852).

COTIZACIÓN. f. La acción y efecto de cotizar (DRAE 1852).

COMANDITA (EN). Com. f. Sociedad mercantil entre varios individuos, de los cuales unos ponen el capital y otros la industria (DRAE 1852 s.v. comandita (en)).

7 Estos mismos procedimientos aparecen señalados en Torruella y Huertas (2018) y Fajardo (1994).

8 El subrayado es nuestro en este ejemplo y en los siguientes de este estudio. 
COMANDITARIO, RIA. adj. Lo perteneciente á la comandita (DRAE 1852 s.v. comanditario, ria).

\section{LA RECEPCIÓN DEL LÉXICO ESPECIALIZADO: ANÁLISIS DEL AUMENTO EN LA $9^{\text {a }}$ Y $10^{\text {a }}$ EDICIONES DEL DRAE}

Según los datos de Freixas (2019), la novena edición añade un total de 530 lemas y 542 formas que contrastan con los 658 lemas y 723 formas nuevas de la décima edición. En la siguiente tabla se recoge la distribución de lemas y la inclusión de voces marcadas con alguna abreviatura diatécnica:

\begin{tabular}{|c|c|c|}
\hline Edición DRAE & Adiciones & Adiciones con marca de especialidad \\
\hline 1843 & 530 & 49 \\
\hline 1852 & 658 & 65 \\
\hline
\end{tabular}

Tabla 3. Distribución del aumento y de lemas marcados en la novena y décima ediciones del DRAE

Entre las voces marcadas de la décima edición, es relevante destacar la inclusión de nueve de ellas en el Suplemento: acetato (Quím.), acético, ca (Quím.), bastanteo (For.), gerencia (Com.), hidropatía (Med.), homeopatía (Med.), nitrato (Quím.), prepositivos (Gram.), reseda (Bot.). En la presencia de este conjunto de lemas se atestigua el deseo de la Corporación de enriquecer el diccionario con adición de voces neológicas modernas que reflejan los últimos avances en la sociedad, como se justifica en el prólogo de la décima edición: "sin variar el plan de la obra ha procurado mejorarla; no solo enriqueciéndola con muchas voces y locuciones que, ó desde antes le faltaban, ó modernamente introducidas se han generalizado en el uso".

Junto a las adiciones, cabe añadir el número de lemas reintroducidos en la novena y décima ediciones y que de acuerdo con Freixas (2019) testimonian "una revisión completa de las definiciones" y asimismo importante para el recuento del aumento. Así, la décima edición presenta una cincuentena de voces reintroducidas desde Autoridades o las primeras ediciones del siglo XIX pero que se suprimen en alguna edición posterior. A continuación se señalan algunos ejemplos de la décima edición?:

\begin{tabular}{|l|l|}
\hline $\begin{array}{l}\text { ICOSAEDRO. s.m. Term. de Geometría. } \\
\text { Es un sólido, contenido de veinte triángulos } \\
\text { equiláteros entre si iguales. Lat. Icosaedrus, } i . \\
\text { (Autoridades, 1734). }\end{array}$ & $\begin{array}{l}\text { ICOSAEDRO. m. Geom. Cuerpo regular, } \\
\text { terminado por veinte triángulos equiláteros. } \\
(D R A E \text { 1852). }\end{array}$ \\
$\begin{array}{l}\text { ICOSAEDRO. s.m. Geom. Es un sólido } \\
\text { contenido de veinte triángulos equiláteros entre } \\
\text { sí iguales. Icosaedrus (DRAE 1780-1791). }\end{array}$ & \\
\hline
\end{tabular}

9 No se señalan las reintroducciones de la novena edición puesto que ya están estudiadas en Freixas 2019. 


\begin{tabular}{|c|c|}
\hline $\begin{array}{l}\text { ESTEREOMETRÍA. s.f. Parte de la Geometría, } \\
\text { que trata de la medida de los cuerpos ó sólidos. } \\
\text { Lat. Stereometria (Autoridades,1732- DRAE } \\
\text { 1783). }\end{array}$ & $\begin{array}{l}\text { ESTEREOMETRÍA. f. La ciencia que trata de } \\
\text { la medida de los sólidos. (DRAE 1852). }\end{array}$ \\
\hline $\begin{array}{l}\text { VIVAQUE. s.m. Quartel pequeño donde en las } \\
\text { Ciudades se acogen los Soldados, que se emplean } \\
\text { para las rondas, y patrullas de parte de noche. } \\
\text { Es voz usada en Andalucía. Lat. Parva meta } \\
\text { castrensis nocturna. (Autoridades, 1739-1791) } \\
\text { VIVAC ó VIVAQUE. s.m. Milic. La guardia que } \\
\text { en las plazas de armas hacen los granaderos en } \\
\text { uno de los parages más públicos de la ciudad. } \\
\text { Statio. (DRAE 1803S). }\end{array}$ & $\begin{array}{l}\text { VIVAQUE. m. Milic. La guardia principal en } \\
\text { las plazas de armas, á la cual acuden todas las } \\
\text { demás á tomar el santo. V. PRINCIPAL. ॥ Suele } \\
\text { darse el mismo nombre de VIVAC Ó VIVAQUE al } \\
\text { campamento de un cuerpo militar (DRAE 1852). }\end{array}$ \\
\hline
\end{tabular}

Tabla 4. Comparación de entradas del $D R A E$ en distintas ediciones.

Como se detallará más adelante (vid. § 4), la reintroducción de las voces en la décima edición se puede explicar por la documentación de estas voces en los diccionarios no académicos de Terreros, Núñez de Taboada o Salvá y en tratados de especialidad ( $c f r$. CORDE). Del mismo modo, las enmiendas efectuadas en las reintroducciones también deben deuda a los repertorios mencionados ${ }^{10}$.

\subsection{Léxico marcado}

En las tablas 1 y 2 (vid. $§ 2.1$.) se ha representado la distribución de las acepciones con marcas diatécnicas en la novena y décima ediciones del $D R A E$ y se han descrito los ámbitos temáticos a los que estas pertenecen.

Las 49 voces especializadas de la novena edición y las 65 de la décima edición representan en su mayoría la renovación de los vocabularios de especialidad a la que alude Gómez de Enterría (2018: 276) en el paso del siglo XVIII al XIX gracias a

el ritmo de difusión que alcanzaron los textos y teorías científicas en el último tercio de la centuria, entendida la difusión no solo a partir de la recepción de ideas foráneas, mediante la traducción masiva de literatura científica, sino también con la participación activa y la contribución eficaz de los científicos españoles en la Ilustración europea (Lafuente et al., 1996: 966). Aunque es evidente que el cauce más activo para el enriquecimiento de la terminología científica fue la traducción de la ciencia a las lenguas vernáculas, al tiempo que las publicaciones científicas en latín iban quedando relegadas a reductos muy limitados.

En este sentido, una amplia parte de las adiciones de la novena y décima ediciones son voces de las ciencias naturales específicas de disciplinas como la botánica, la farmacología, la medicina y cirugía, la zoología o la mineralogía. El auge de los lemas de la química en la décima edición y en su Suplemento (acetato (1852 S), acético (1852 S), carbonato, cloroni-

10 Así, la redacción de la voz estereometría en la décima edición coincide con la del diccionario de Núñez de Taboada (1825). En el $\S 4$ se aportan ejemplos de definiciones. 
trato, sulfato $(1852 \mathrm{~S})$ ) se explica por la importancia de las traducciones de la terminología química francesa, como ha demostrado ampliamente Garriga (1996, 1996-97, 1997). En esta área se establece un sistema de patrones derivativos (sufijos -ato, -ico, -oso, uro) para nombrar a los diferentes tipos de sales y compuestos químicos (vid. Muñoz 2015).

Además de las traducciones, cabe destacar la atención que los académicos otorgaron a los tratados científicos de las autoridades más célebres como fuentes para la inclusión de las voces de especialidad en las dos ediciones académicas, criterio especificado en las Reglas de 1838 (vid. § 2). A modo de ejemplo y como se ha demostrado en Freixas (2019), una parte de lemas adicionados en las ediciones de la segunda mitad del siglo XIX se debe a la contribución de Gregorio García del Pozo o Ramón de Salas.

Junto a los dominios anteriores, otro conjunto de voces refleja campos tradicionalmente representados en las ediciones del DRAE como la historia natural (estalactita, mandril, portaalmizcle, (DRAE 1843), la milicia (carronada, desfile, dispersar, escalafon, pontonero (DRAE 1843); racionar (DRAE 1852)) o la náutica (escuna, orientar, troceo (DRAE 1843); descalcador, descalcar, descalimar, farola (2a acep) muz, toar, trincadura (DRAE 1852)).

Desde una perspectiva formal, destacan los derivados creados normalmente por un proceso de sufijación (amaneramiento borriquete, espontanearse, indagatorio, mucosidad (DRAE 1843); carnificación, churrigueresco, manipulación, racionar, vertedera (DRAE 1852). En los ámbitos de las ciencias naturales son frecuentes las voces con formantes grecolatinos especialmente en voces de la cirugía y medicina (amaurosis, etopeya, gástrico (DRAE 1843), litotomía, hidropatía, homeopatía, odontalgia (DRAE 1852)), y en la geometría (exaedro (DRAE 1843); dodecaedro, duodecágano, icosaedro (DRAE 1852)).

\subsection{Léxico no marcado}

En este segundo apartado, dedicado a los lemas no marcados ${ }^{11}$, se ha localizado un conjunto de neologismos que, salvo a no presentar una marca diatécnica, responde a realidades vigentes en la época. La ausencia de marcación en estos lemas puede atribuirse a la ausencia de una autoría prestigiosa:

\begin{tabular}{|c|c|c|c|c|}
\hline $\begin{array}{l}\text { cánula } \\
\text { cotización } \\
\text { comanditario, ra } \\
\text { charanga }\end{array}$ & $\begin{array}{l}\text { daguerreotipia } 1852 \mathrm{~S} \\
\text { daguerreotipo } 1852 \mathrm{~S} \\
\text { fotografia } 1852 \mathrm{~S} \\
\text { fotográfico } 1852 \mathrm{~S} \\
\text { fotógrafo } 1852 \mathrm{~S}\end{array}$ & $\begin{array}{l}\text { ferrocarril } \\
\text { ferretería }\end{array}$ & $\begin{array}{l}\text { favoritismo } \\
\text { federalismo } \\
\text { filosofismo } \\
\text { inglesismo } \\
\text { italianismo } \\
\text { jacobinismo } \\
\text { optimismo } \\
\text { panteísmo } \\
\text { prosaísmo } \\
\text { protestantismo } \\
\text { provincialismo } \\
\text { romanticismo } \\
\text { socialismo }\end{array}$ & \begin{tabular}{|l} 
calculista \\
floretista \\
folletinista operista \\
optimista pianista \\
ordenancista \\
socialista \\
trapisondista
\end{tabular} \\
\hline
\end{tabular}

Tabla 5. Voces no marcadas en la décima edición (DRAE 1852).

11 El análisis se centra en las voces de la décima edición (1852) puesto que en Freixas (2019) ya se describen las voces no marcadas en la novena edición (1843). 
En primer lugar, las voces de la primera columna de la tabla 5 representan un ejemplo de la práctica lexicográfica académica de hacer referencia a un ámbito de especialidad en su definición pero sin recibir una marca diatécnica. Así, la esfera de la cirugía se alude en la voz cánula, la del comercio en cotización y comanditario, ra (por vinculación respectivamente al lema cotizar y comandita (en) que presentan la marca Com.) y la militar en la voz charanga.

En segundo lugar, los lemas de la segunda columna pertenecen al dominio léxico de la fotografía y de aparecer incluidos en el Suplemento de la décima edición. La ausencia de la abreviatura Fot. en la lista de abreviaturas hasta la edición de 1899 podría ser el motivo de su ausencia en la décima edición. El lema daguerreotipia remite a fotografía y se elimina en la decimotercera edición (1899). El sustantivo daguerreotipo se crea a partir del nombre del inventor de la máquina de fotografía, Daguerre, como se señala en la definición del $D R A E$ (1852) y también se elimina en la decimotercera edición:

DAGUERREOTIPO. m. Máquina que sirve para las operaciones fotográficas. Ha recibido este nombre del de su inventor, Daguerre.

Las tres voces restantes pertenecen a la misma familia léxica y, a diferencia de las dos anteriores, han pervivido hasta la 23. ${ }^{\text {a }}$ edición (2014) pero no se han marcado en ninguna de las ediciones, posiblemente por la difusión de este tipo de términos en la lengua general. Prueba de ello es la adición de derivados fácilmente formables de la misma familia en las ediciones siguientes: así, en la decimotercera edición se registran 12 lemas, todos ellos sin ninguna marca diatécnica: fotogénico, ca, fotograbado, fotográficamente, fotolitografía, fotolitografiar, fotolitográficamente, fotolitográfico, ca, fotometría, fotométrico, ca, fotómetro, fototipografía, fototipográfico,ca.

Mediante los lemas de la tercera columna de la tabla 5 se ha querido representar la inclusión en la décima edición (1852) de conceptos vinculados a la esfera de la industria y el comercio. Como se ha demostrado anteriormente, en el prólogo se alude a la inclusión de voces de estos ámbitos. Del mismo modo que con la familia léxica de las voces de la fotografía, estos dos lemas también pertenecen a otra familia de derivados, la relacionada con el significado de 'hierro'. Sobre la primera de ellas, Rodríguez (1996) dedicó un amplio estudio a la historia del léxico del ferrocarril, basándose en sus documentaciones en textos especializados y en lexicografía no académica y académica. En particular, los primeros términos del léxico del ferrocarril se documentan entre 1829 y 1835 (1996: 161) y se consolidan entre 1851-1862, motivo por el cual la Academia incorpora esta voz en la décima edición.

Por su parte, la voz ferretería que remite al lema ferrería en la décima edición, en futuras ediciones se amplía semánticamente ( 2 acepciones en 1852, 3 acepciones en 1970, 4 en 1984) y se consolida para expresar la tienda o actividad comercial en la que se venden objetos de metal o hierro. La remisión a ferrería queda relegada a un uso más concreto, referente al taller en el que se trabaja con el hierro:

FERRETERÍA. f. ferrería $\|$ El comercio de hierro (DRAE1852)

FERRETERÍA. (De ferrete). f. ferrería \| 2. El comercio de hierro. \| 3. Conjunto de objetos de hierro que se venden en las ferreterías, como cerraduras, clavos, herramientas, vasijas, etc. (DRAE 1970). 
FERRETERÍA. (De ferrete). f. ferrería \| 2. Tienda donde se venden diversos objetos de metal o de otras materias, como cerraduras, clavos, herramientas, vasijas, etc. $\| 3$. Conjunto de objetos de hierro que se venden en las ferreterías.\| 4. El comercio de hierro. \|. (DRAE 1984).

Finalmente, en las dos últimas columnas se ha recogido un conjunto de neologismos que poseen en común pertenecer a los derivados creados mediante los sufijos -ismo e $-i s t a^{12}$. Como se ha demostrado en Muñoz (2010, 2012), se trata de un grupo de voces cuya inclusión en el DRAE aumenta progresivamente en cada una de las ediciones de los siglos XIX y XX y que responde a realidades y conceptos intelectuales del contexto sociocultural, económico, histórico-político, artístico-cultural, comercial y profesional de las sociedades española y europea. Así, las voces en -ismo suelen designar doctrinas de diversa índole (federalismo, filosofismo, jacobinismo, optimismo, socialismo) que acostumbran a tener un equivalente en -ista para aludir al partidario o seguidor de dicha teoría (optimista, socialista). En el resto de valores el morfema -ista aporta otros significados como el de las profesiones (floretista, pianista, folletinista ${ }^{13}$ ). La adición de voces con ambos morfemas es el ejemplo que corrobora el logro de las intenciones de la Academia por incorporar "gradualmente los progresos de la lengua, y apuntando, como un cronista, las innovaciones que introduce y generaliza el uso de las gentes instruidas y en particular de los escritores que procuran explicarse con propiedad y pureza" (DRAE 1843: Prólogo).

\section{LA INFLUENCIA DE LOS DICCIONARIOS NO ACADÉMICOS EN EL AU- MENTO DE LA NOVENA Y DÉCIMA EDICIONES DEL DRAE}

En páginas anteriores (vid. $\S 1$. Introducción), se ha señalado la polémica intelectual que tuvo lugar a partir de primera mitad del siglo XIX en la lexicografía española monolingüe sobre los neologismos y su ritmo de admisión en la Academia; el Prólogo de la novena edición constituye una defensa a los ataques que la Corporación recibe en este periodo por ser acusada de mantener unos criterios muy restrictivos con respecto a los neologismos y extranjerismos.

Los diccionarios de Terreros (1786-1793), Núñez de Taboada (1825) Peñalver (1842) y Salvá (1846) son anteriores a la novena y décima edición y todos ellos comparten, a grandes rasgos, dos constantes. En primer lugar, los diccionarios no académicos de este periodo presentan unos comportamientos divergentes al DRAE frente a la admisión de los tecnicismos (Ahumada 2000, Alvar Ezquerra 1993a, Azorín 2000, Seco 1987) y una simple lectura de los prólogos de ambas corrientes lexicográficas, la oficial y la no académica, permite verificar los diferentes criterios que subyacen a los diccionarios.

En segundo lugar, los repertorios no académicos coinciden en presentar el mayor número posible de derivados procedentes de la lengua común o de otras áreas especializadas de la ciencia o la técnica. Precisamente el título de estas obras ${ }^{14}$ revela el nacimiento de una nueva

12 En la definición de algunas de estas voces se especifica con la información "Es voz nuevamente introducida" el carácter neológico de estos lemas.

13 Freixas (2019) sostiene que la novena edición destaca por su amplia documentación en la literatura de los siglos XVIII y XIX. En este sentido, destaca la voz folletinista que designa al escritor de folletines, género literario muy desarrollado en la literatura española del siglo XIX.

14 Diccionario castellano con las voces de ciencias y artes y sus correspondientes en las tres lenguas francesa, latina e italiana [...] de Terreros (1786); Diccionario de la lengua castellana, para cuya composición se han 
tendencia en la lexicografía española que pretende acumular la mayor parte de los saberes existentes en todas las áreas del conocimiento: el diccionario enciclopédico. Según Seco (1987) y Azorín (2000: 247) "los antecedentes de este proceder se encontraban en la obra de Terreros" y en la lexicografía francesa de Bescherelle (1843) (vid. Muñoz 2007). A diferencia del Diccionario académico, la mayoría de las obras no académicas evoluciona con un ritmo paralelo a los cambios históricos que tienen lugar en la sociedad española, pues "responden al progreso de los tiempos" (Seco 1987: 135); esto es, intentan "difundir aquellos conocimientos que, en cada momento histórico, vinculan a una comunidad lingüística determinada con su entorno cultural inmediato" (Azorín 1992: 448). Prueba de ello, es la temprana incorporación en los diccionarios no académicos de un considerable número de tecnicismos cuya admisión es posterior en las ediciones del DRAE. En las tablas 6 y 7, se ha representado la documentación en alguno de los diccionarios de Terreros, Núñez de Taboada o Salvá en los lemas marcados con alguna marca diatécnica en la novena y décima edición del DRAE:

\begin{tabular}{|l|l|l|l|}
\hline & LEMA (DRAE 1843) & MARCA & $\begin{array}{l}\text { DICCIONARIOS } \\
\text { ANTERIORES }\end{array}$ \\
\hline 1 & aberración & Astr. & Terreros / Salvá \\
\hline 2 & culminante & Astr. & Terreros / Salvá \\
\hline 3 & deviación & Astr. & Terreros / Salvá \\
\hline 4 & lumbar & Anat. & Salvá \\
\hline 5 & vertebrado & Anat & Salvá \\
\hline 6 & entramar & Arq. & Salvá \\
\hline 7 & tortillos & Blas. & Salvá \\
\hline 8 & liquen & Bot. & Terreros / Núñez \\
\hline 9 & borriquete & Carp. & Salvá \\
\hline 10 & traqueotomía & Cir. & Salvá \\
\hline 11 & torso & Esc. & Salvá \\
\hline 12 & condómino & for & Salvá \\
\hline 13 & espontanearse & for & Salvá \\
\hline 14 & excarceración & for & Salvá \\
\hline 15 & incautarse & for & Salvá \\
\hline 16 & indagatorio & for & Salvá \\
\hline 17 & infringir & for & Salvá \\
\hline 18 & interdicto & for & Salvá \\
\hline
\end{tabular}

consultado los mejores vocabularios de esta lengua y el de la Real Academia Española, últimamente publicado en 1822; aumentado con más de 5000 voces o artículos que no se hallan en ninguno de ellos de Núñez de Taboada (1825); Nuevo diccionario de la lengua castellana, que comprende la última edición íntegra, muy rectificada y mejorada del publicado por la Academia Española, y unas veinte y seis mil voces, acepciones, frases y locuciones, entre ellas muchas americanas [...] de Salvá (1846). 


\begin{tabular}{|c|c|c|c|}
\hline & LEMA (DRAE 1843) & MARCA & $\begin{array}{l}\text { DICCIONARIOS } \\
\text { ANTERIORES }\end{array}$ \\
\hline 19 & premoriente & for & Salvá \\
\hline 20 & refeccionario & for. & Salvá \\
\hline 21 & aspillera & Fort. & Salvá \\
\hline 22 & parapetarse & Fort. & - \\
\hline 23 & orientar & Geog. & Terreros / Salvá \\
\hline 24 & exaedro & Geom. & Salvá \\
\hline 25 & elision & Gram. & Salvá \\
\hline 26 & estalactita & Hist. nat. & Núñez \\
\hline 27 & mandril & Hist. nat. & Salvá \\
\hline 28 & portaalmizcle & Hist. nat. & Salvá \\
\hline 29 & entredos & Impr. & Salvá \\
\hline 30 & iniciativa & leg. & Salvá \\
\hline 31 & amáurosis & Med. & Terreros \\
\hline 32 & asfixia & Med. & Terreros /Núñez \\
\hline 33 & deletéreo & Med. & Salvá \\
\hline 34 & deviacion & Med. & Terreros \\
\hline 35 & gástrico & Med. & Núñez \\
\hline 36 & mucosidad & Med. & Salvá \\
\hline 37 & protuberancia & Med. & Salvá \\
\hline 38 & carronada & Milic. / Mil. & - \\
\hline 39 & desfile & Milic. / Mil. & - \\
\hline 40 & dispersar & Milic. / Mil. & - \\
\hline 41 & escalafon & Milic. / Mil. & - \\
\hline 42 & pontonero & Milic. / Mil. & - \\
\hline 43 & arpegio & Mús. & Núñez \\
\hline 44 & escuna & Náut. & - \\
\hline 45 & orientar & Náut. & Terreros \\
\hline 46 & troceo & Náut. & Terreros \\
\hline 47 & amaneramiento & Pint. & - \\
\hline 48 & esfumino & Pint & - \\
\hline 49 & etopeya & Ret. & Terreros \\
\hline
\end{tabular}

Tabla 6. Documentación de las voces especializadas de la novena edición en los diccionarios no académicos (Terreros, Núñez de Taboada y Salvá). 


\begin{tabular}{|c|c|c|c|}
\hline & $\begin{array}{l}\text { LEMA (DRAE } \\
1852 \text { ) }\end{array}$ & MARCA & $\begin{array}{l}\text { DICCIONARIOS } \\
\text { ANTERIORES }\end{array}$ \\
\hline 1 & vertedera & Agric. & Salvá \\
\hline 2 & crispar & Anat. & - \\
\hline 3 & pélvis & Anat. & Terreros / Salvá \\
\hline 4 & yeyuno & Anat. & Salvá \\
\hline 5 & churrigueresco & Arq. & Salvá \\
\hline 6 & labra & Arq. & Salvá \\
\hline 7 & $\begin{array}{l}\text { salmer } \\
\text { (reintroducción) }\end{array}$ & Arq. & - \\
\hline 8 & reseda & Bot. & Terreros / Salvá \\
\hline 9 & infarto & Cir. & - \\
\hline 10 & litotomía & Cir. & Terreros / Núñez \\
\hline 11 & litotricia & Cir. & - \\
\hline 12 & odontalgia & Cir. & Núñez / Salvá \\
\hline 13 & comandita (en) & Com. & - \\
\hline 14 & cotizar & Com. & - \\
\hline 15 & cupon & Com. & - \\
\hline 16 & gerencia & Com. & - \\
\hline 17 & demulcente & Farm. & Salvá \\
\hline 18 & manipulacion & Farm. & Terreros /Núñez / Salvá \\
\hline 19 & bastanteo & For. & - \\
\hline 20 & condominio & For. & Salvá \\
\hline 21 & obtentor & For. & Salvá \\
\hline 22 & ponencia & For. & - \\
\hline 23 & probatoria & For. & - \\
\hline 24 & dodecaedro & Geom. & Terreros /Núñez \\
\hline 25 & duodecágano & Geom. & \\
\hline 26 & $\begin{array}{l}\text { icosaedro } \\
\text { (reintroducción) }\end{array}$ & Geom. & - \\
\hline 27 & romboidal & Geom. & Salvá \\
\hline 28 & apódosis & Gram. & Terreros \\
\hline 29 & prepositivos & Gram. & - \\
\hline 30 & portulano & Hidrogr. & Salvá \\
\hline 31 & estalacmita & Hist. nat & - \\
\hline 32 & maculatura & Impr. & Terreros / Salvá \\
\hline 33 & versalita & Impr. & - \\
\hline 34 & infinitesimal & Mat. & Terreros / Salvá \\
\hline
\end{tabular}




\begin{tabular}{|c|c|c|c|}
\hline & $\begin{array}{l}\text { LEMA (DRAE } \\
1852)\end{array}$ & MARCA & $\begin{array}{l}\text { DICCIONARIOS } \\
\text { ANTERIORES }\end{array}$ \\
\hline 35 & polinomio & Mat. & Terreros / Salvá \\
\hline 36 & afta & Med. & Terreros / Salvá \\
\hline 37 & carnificación & Med. & Terreros / Núñez /Salvá \\
\hline 38 & emuntorio & Med. & Terreros \\
\hline 39 & hidropatía (1852 S) & Med. & - \\
\hline 40 & homeopatia (1852 S) & Med. & - \\
\hline 41 & profiláctica & Med. & Terreros \\
\hline 42 & tétanos & Med. & Terreros (s.v. tétano) \\
\hline 43 & racionar & Mil. & - \\
\hline 44 & $\begin{array}{l}\text { vivaque } \\
\text { (reintroducción) }\end{array}$ & Milic. & Salvá \\
\hline 45 & sílice & Min. & Salvá \\
\hline 46 & descalcador & Náut. & - \\
\hline 47 & descalcar & Náut. & - \\
\hline 48 & descalimar & Náut. & - \\
\hline 49 & farola $\left(2^{a}\right.$ acep $)$ & Náut. & Salvá \\
\hline 50 & $m u z$ & Náut. & Terreros / Salvá \\
\hline 51 & toar & Náut. & Salvá \\
\hline 52 & trincadura & Náut. & Salvá \\
\hline 53 & amanerarse & Pint. & - \\
\hline 54 & lontananza & Pint. & Terreros / Núñez \\
\hline 55 & astur & Poet. & - \\
\hline 56 & ponto & Poét. & Salvá \\
\hline 57 & procela & Poét. & - \\
\hline 58 & rielar & Poét. & Salvá \\
\hline 59 & rigente & Poét. & Salvá \\
\hline 60 & acetato $(1852 \mathrm{~S})$ & Quím. & Salvá \\
\hline 61 & acético (1852 S) & Quim. & - \\
\hline 62 & carbonato & Quim. & - \\
\hline 63 & cloro & Quím. & Salvá \\
\hline 64 & nitrato & Quím. & Núñez \\
\hline 65 & sulfato (1852 S) & Quím. & - \\
\hline
\end{tabular}

Tabla 7. Documentación de las voces especializadas de la décima edición en los diccionarios no académicos (Terreros, Núñez de Taboada y Salvá). 
Los datos de las tablas 6 y 7 corroboran una pronta documentación de muchas de las voces diatécnicas de la novena y décima ediciones en los repertorios no académicos seleccionados. Ello, en parte, puede justificarse por la labor de corrección y ampliación del contenido del Diccionario académico que realizaron Núñez de Taboada o Salvá respecto a la edición anterior que precedió a la publicación de su obra, como bien se especifica en la portada de sus repertorios léxicos.

Un detenido cotejo de las definiciones de las voces de las tablas anteriores en ambos tipos de diccionarios (edición académica y repertorios no académicos) permite detectar, en algunos casos, el seguimiento por parte de la Academia de incluir también los lemas que se recogen en Terreros y en lexicógrafos posteriores. A continuación, se señalan dos ejemplos en los lemas carnificación y manipulación:

CARNIFICACIÓN. termino de la Medicina, es la conversion de algun hueso, \&c. en carne. Fr. Carnification, V. Transmutacion. [Terreros (1786-1793)].

CARNIFICACION. s.f. Transformación de los huesos en carne. [Núñez de Taboada 1825]. CARNIFICACION. f. Med. El acto y efecto de carnificarse. [Salvá 1846].

CARNIFICACION. Med. El acto y efecto de criar carne las heridas al cicatrizarse. [DRAE 1852].

MANIPULACION. separacion, ó mecanismo que usan los Mineros para sacar de las piedras y tierras el oro y la plata. Fr. Manipulation. Lat. Collectio glebarum aurearum. Por la semejanza se dice manipulación, por lo mismo que maneja. V. [Terreros (1786-1793)]. MANIPULACION. s.f. La acción de manipular. [Núñez de Taboada 1825].

MANIPULACION. f. OPERACIÓN. Es voz usada en la farmacia, química y otras artes. [Salvá 1846].

MANIPULACION. f. Farm. Confeccion de un medicamento. \| met. La accion y efecto de manipular [DRAE 1852].

En los ejemplos anteriores se refleja la influencia que pudieron ejercer los diccionarios no académicos en los lemas añadidos en las ediciones académicas de mediados del siglo XIX. Así, la información especializada de estas voces pudo ser decisiva al añadir las voces en el Diccionario oficial con su correspondiente marca diatécnica. De la misma manera, la decisión de reintroducir lemas en la décima edición pudo venir motivada por la documentación previa de algunos lemas en los diccionarios no académicos señalados. Por ejemplo, la voz salmer se admite en la cuarta edición (1803) y se suprime en la edición académica siguiente (1817) y no se reintroduce hasta la décima edición (1852), probablemente por su presencia en el diccionario de Salvá (1846), y se mantiene hasta la vigésimatercera edición:

SALMER. s.m. Arq. El plano inclinado de la imposta, machon, muro, \&c. de donde arranca el arco ó bóveda escarzana. Columna pars è qua tectum incurvum, vel arcus assurgit. [DRAE 1803].

SALMER. m. Arq. El plano inclinado de la imposta, machon, muro, etc. de donde arranca el arco ó bóveda escarzana. Columna pars è qua tectum incurvum, vel arcus assurgit. [Salvá 1846].

SALMER. m. Arq. El plano inclinado de la imposta, machon, muro, etc. de donde arranca el arco ó bóveda escarzana. Columna pars è qua tectum incurvum, vel arcus assurgit. [DRAE 1852]. 
En este sentido, mediante los ejemplos anteriores puede sostenerse que junto a los tratados de especialidad y las traducciones de las obras especializadas (Garriga 1996, 1996-97, 1997; Gómez de Enterría 2018), las obras lexicográficas de los diccionarios no académicos constituyeron una tercera fuente para poder asegurar la generalización de los términos especializados en la lengua común.

\section{CONCLUSIONES}

En la presente contribución se ha realizado un primer acercamiento a la caracterización del léxico especializado en las dos ediciones centrales del siglo XIX: DRAE 1843 y DRAE 1852. Mediante la información que nos han proporcionado los prólogos de ambas ediciones y las Reglas de 1838 se ha descrito cómo la Academia concibe el léxico de especialidad en este periodo.

En primer lugar, se ha demostrado que la Corporación sigue la tradición desde el Diccionario de autoridades puesto que continúan siendo representativas marcas diactécnicas como la náutica, la botánica o la historia natural. Otras marcas (Com., Quím.) reflejan la difusión social de otras áreas, como el comercio, la química y la industria, en general, ámbitos que se mencionan en el prólogo de la décima edición (1852).

En segundo lugar, se ha destacado que en el léxico marcado subyace una perspectiva pragmática, puesto que la Academia aboga por testimoniar las palabras que se marcan según su nivel de especialidad y no según su ámbito especializado teniendo en cuenta el criterio de generalización de las voces o uso restringido en algunos ámbitos. De acuerdo con esta concepción, en el presente estudio se han señalado tres procedimientos de indicación de la especialidad: (1) presencia de marca diatécnica: un total de 49 adiciones con marca de especialidad en la novena edición y 65 en la décima. Normalmente, la Academia sigue la tradición anterior y la adjudicación de las marcas no presenta notables cambios; en este sentido coincidimos con los resultados de Torruella y Huertas (2018) para la quinta edición y Freixas (2019) para la novena edición sobre una falta de sistematicidad en la atribución de las marcas; (2) ausencia de marca pero con la indicación de especialidad insertada en la definición: este procedimiento es herencia del Diccionario de autoridades y sigue estando presente en las ediciones de 1843 y 1852; (3) la información de especialidad se deduce por la relación del lema con otros de la misma familia léxica que sí que aparecen con marca; este modo de indicación de especialidad se encuentra, especialmente, en los adjetivos relacionales.

En tercer lugar, los neologismos no marcados se consideran un corpus muy valioso puesto que representan gran parte de la composición del léxico moderno contemporáneo. Se trata de ámbitos de nuevas disciplinas (la política, la retórica, la fotografía, la química, la terminología lingüística, etc.) que describen nuevas realidades. En el presente estudio, se ha detallado un grupo de derivados en -ismo e ista y otros lemas que se consideran términos clave de los avances en la sociedad contemporánea: cotización, ferretería, ferrocarril, folletinista, fotografía, socialismo.

Finalmente, otro de los resultados de la indagación ha sido corroborar la influencia de los diccionarios no académicos en la entrada de lemas especializados en la novena y décima ediciones, así como de reintroducciones, correspondientes a voces incluidas en el Diccionario de autoridades o en las primeras ediciones del siglo XIX pero suprimidas en 
alguna edición posterior. La presencia de algunos términos recogidos desde el Diccionario de Terreros y mantenidos en las obras no académicas de Núñez de Taboada o Salvá pudo ser decisiva para su entrada en la nómina de las ediciones académicas de mediados del siglo XIX. De este modo, representan una fuente más, junto a las traducciones y a los tratados de especialidad, para testimoniar el uso extendido de las voces, criterio que la Corporación defiende en los sucesivos prólogos.

Por último, se coincide con Freixas (2019) en la importancia de tener en cuenta la posible relación existente entre la presencia de marcas y las posibles fuentes de especialidad consultadas, dado que la asignación de la abreviatura diatécnica se produce cuando esta información se extrae de textos especializados de prestigiosas autoridades, criterio que se postula en las Reglas de 1838 y se defiende en las ediciones académicas. El estudio de la relación señalada entre marca y fuente especializada podrá ser clave para entender mejor los criterios de la Academia y, consecuentemente, interpretar mejor la ausencia de marca en los neologismos más modernos.

\section{REFERENCIAS BIBLIOGRÁFICAS}

Alvar Ezquerra, M. (1983). "Los prólogos del Diccionario académico. Nomenclatura específica y microestructura", Revista de Filología Española, LXIII, pp. 205-222.

Alvar Ezquerra, M. (1992). "Los diccionarios académicos y el problema de los neologismos". En C. G. Reigosa (coord.). El neologismo necesario. Madrid: Fundación EFE, pp. 51-70.

Álvarez de Miranda, P. (2001). "La lexicografía académica de los siglos XVIII y XIX”. En I. Ahumada (coord.). Cinco siglos de lexicografia del español. Jaén: Universidad de Jaén, pp. 35-61.

Azorín, D. (1994-1995). "El Nuevo Diccionario de la Lengua Castellana de Vicente Salvà", Estudios de Lingüistica de la Universidad de Alicante, 10, pp. 9-20.

Azorín, D. (1996). "La lexicografía española en el siglo XIX: Desarrollos y tendencias". En E. Serra et al., Panorama de la investigación lingüistica a l'Estat Espanyol. Valencia: Universitat de València, pp. 48-54

Azorín, D. (1996-1997). "La lexicografía española en el siglo XIX: del diccionario a la enciclopedia", Estudios de Lingüística de la Universidad de Alicante, 11, pp. 111-122.

Azorín, D. (2000). Los diccionarios del español en su perspectiva histórica. Alicante: Publicaciones de la Universidad de Alicante.

Azorín, D. (2002). "Salvá y la Academia Española: dos posturas frente a la recepción de tecnicismos en el diccionario de la lengua". En Esparza, M. A. et alii (eds.). Estudios de historiografia lingüistica. Actas del III Congreso Internacional de la Sociedad Española de Historiografía Lingüística. Hamburg: Helmut Buske, pp. 777-788.

Azorín, D. (2003). "Neologismos incorporados por Salvá en el Nuevo Diccionario de la Lengua Castellana", Estudios de Lingüistica. Revista de Lengua Española y Lingüística General, 17, pp. 107-139.

Azorín, D. (2018). "El léxico con marcación estilística". En Clavería, G. y M. Freixas (2018a). El diccionario de la Academia en el siglo XIX: la 5. ${ }^{a}$ edición (1817) al microscopio. Madrid: Arco/ Libros, pp. 427-458.

Azorín, D. y Rosario Baquero Mesa (1994-1995). "De la teoría a la práctica lexicográfica: El Nuevo diccionario de la lengua castellana de Vicente Salvá", Estudios de Lingüística de la Universidad de Alicante, 10, pp. 9-20.

Battaner, M. ${ }^{\text {a }}$. (1996). "Terminología y diccionarios". En Jornada panllatina de terminología. Perspectives i camps d'aplicació. Barcelona: IULA, pp. 93-117. 
Baquero Mesa, R. (1992). "Notas en contribución a la historia de la lexicografía española monolingüe del siglo XIX”. En Euralex'90 Proceedings. Actas del I V Congreso Internacional.Barcelona: Bibliograf, pp. 455- 461.

Cabré, M. ${ }^{a}$ T. (1992): La terminología. La teoría, els mètodes, les aplicacions. Barcelona: Empúries.

Carriazo, J.R. y Gómez, M. (2010). "La marcación de especialidad". En M. Gómez y J.R. Carriazo (eds.). La marcación en lexicografía histórica. San Millán de la Cogolla: Cilengua, pp. 243-315.

Carriet, E. (2017). "La séptima edición del diccionario académico (DRAE 1832)", Revista de Lexicografia, 23, pp. 39-65.

Clavería, G. (2003). "La Real Academia Española a finales del siglo XIX: el Diccionario de la lengua castellana de 1899 (13. a edición)”, Boletín de la Real Academia Española, LXXXIII, pp. 255-336.

Clavería, G. (2007). "Historia del léxico en los diccionarios: la deuda del Diccionario de la lengua castellana de la Real Academia Española con los diccionarios de M. Núñez de Taboada”, Revista de Historia de la Lengua Española, 2, pp. 3-27.

Clavería, G. (2016). De vacunar a dictaminar: la lexicografía académica decimonónica y el neologismo. Madrid/Frankfurt: Iberoamericana/Vervuert.

Clavería, G. y Freixas, M. (coords.) (2018a). El diccionario de la Academia en el siglo XIX: la quinta edición (1817) al microscopio. Madrid: Arco/Libros.

Clavería, G. y Freixas, M. (2018b). "El NTLLE: un museo lexicográfico como base de datos lingüísticos y lexicográficos", Cuadernos del Instituto Historia de la Lengua, 11, pp. 117-138.

$C O R D E=$ Real Academia Española: Corpus diacrónico del español. Banco de datos, <http://www. rae.es>.

Diccionario de autoridades = Real Academia Española (1726-1739): Diccionario de la lengua castellana, en que se explica el verdadero sentido de las voces, su naturaleza y calidad con las phrases o modos de hablar, los proverbios o refranes, y otras cosas convenientes al uso de la lengua. 6 vols. Madrid: Imprenta Francisco del Hierro.

Diccionario de autoridades (1770) = Real Academia Española (1770): Diccionario de la lengua castellana, segunda impresión corregida y aumentada. Tomo primero: A-B. Madrid: Joachin Ibarra.

DRAE 1837 = Real Academia Española (1837): Diccionario de la lengua castellana, octava edición. Madrid: Imprenta Nacional.

DRAE 1843 = Real Academia Española (1843): Diccionario de la lengua castellana, novena edición. Madrid: Imprenta de D. Francisco María Fernández.

DRAE 1852 = Real Academia Española (1852): Diccionario de la lengua castellana, décima edición. Madrid: Imprenta Nacional.

DRAE 1869 = Real Academia Española (1869): Diccionario de la lengua castellana, undécima edición. Madrid: Imprenta de Don Manuel Rivadeneyra.

DRAE 1884 = Real Academia Española (1884): Diccionario de la lengua castellana, duodécima edición. Madrid: Imprenta de D. Gregorio Hernando.

DRAE 1899 = Real Academia Española (1899): Diccionario de la lengua castellana, decima tercia edición. Madrid: Imprenta de los Sres. Hernando y compañía.

DRAE 2014 = Real Academia Española y Asociación de Academias de la Lengua Española (2014): Diccionario de la lengua española, vigesimotercera edición. Madrid: Espasa.

Esparza Torres, M. Á. (1999). "La lexicografía monolingüe española del siglo XIX: un conflicto de paradigmas", Romanistik in Geschichte und Gegenwart, 5/1, pp. 49-65.

Fajardo, A. (1994). "La marcación técnica en la lexicografía española”,Revista de Filología de la Universidad de La Laguna, 13, pp.131-143.

Freixas, M. (2019). "La lexicografía académica de mediados del siglo XIX: el aumento de voces en la novena edición del DRAE (1843)”. En Azorín, D.; Clavería, G. y Jiménez Ríos, E. (Eds.). ELUA. El diccionario de la Academia y su tiempo: lexicografia, lengua sociedad en la primera mitad del siglo XIX, Anexo V. 
García Platero, J. M. (2003). "La lexicografía no académica en los siglos XVIII y XIX”. En Medina Guerra, A. M. (coord.). Lexicografía española. Barcelona: Ariel, pp. 263-280.

Garriga, C. (1997). "La recepción de la Nueva nomenclatura química en español”, Grenzgänge (Leipzig), 8, pp. 33-48.

Garriga, C. (1998). "Química, enseñanza y divulgación de la terminología: las Lecciones de química teórica y práctica de Morveau, Maret y Durande”. En Brumme, J. (ed.). La historia de los lenguajes iberorrománicos de especialidad (siglos XVII-XIX); soluciones para el presente. Barcelona: UPF, pp. 163-174.

Garriga, C. (1998). "Luis Proust y la consolidación de la terminología química en español”. En García, J. L. et al.(eds.). VI Congreso de la Sociedad Española de Historia de las Ciencias y de las Técnicas. Segovia: Junta de Castilla y León, pp. 691-699.

Garriga, C. (1998). "El Diccionario Universal de Física de Brisson (1796-1802) y la fijación lexicográfica de la terminología química en español”. En García Turza, C. et al. (eds.). Actas del IV Congreso Internacional de Historia de la Lengua Española. Logroño: AHLE - Gobierno de La Rioja - Universidad de La Rioja, pp. 179-190.

Garriga, C. (2001). "Notas sobre el vocabulario de la química orgánica en español: Liebig y la divulgación de los derivados en -ina". En Bargalló, M. et. al. (eds.). Las lenguas de especialidad y su didáctica. Tarragona: Universitat Rovira i Virgili, pp. 169-180.

Garriga, C. (2002). "Notas sobre la incorporación de los términos de elementos químicos al español en el siglo XIX: el léxico histórico y sinonímico de F. Hoefer”. En Pöll, B. y F. Rainer (eds.). Vocabula et vocabularia: Études de lexicologie et de (méta-)lexicographie romanes en l'honneur du 60è anniversaire de Dieter Messner. Frankfurt am Main: Peter Lang, pp. 131-144.

Garriga, C. (2003). "La química y la lengua española en el siglo XIX", Asclepio, LV / 2, Madrid, CSIC, pp. 93-117.

Garriga, C. (2018). "Las voces de la química”. En Clavería, G. y M. Freixas (2018). El diccionario de la Academia en el siglo XIX: la 5. 'e edición (1817) al microscopio. Madrid: Arco/Libros, pp. 313-337.

Gómez de Enterría, J. (2018). "Las voces de las ciencias naturales y áreas afines”. En Clavería, G. y M. Freixas(2018a). El diccionario de la Academia en el siglo XIX: la 5. ${ }^{a}$ edición (1817) al microscopio. Madrid: Arco/Libros, pp. 275-311.

Gutiérrez Rodilla, B. M. (1998). La ciencia empieza en la palabra: análisis e historia del lenguaje científico. Barcelona: Ediciones Península.

Jiménez Ríos, E. (2013). La crítica lexicográfica y el Diccionario de la Real Academia Española. Obras y autores contra el Diccionario. Anexos de la Revista de Lexicografía, 21.A Coruña: Universidade da Coruña.

Jiménez Ríos, E. (2018). "El léxico con marcación diacrónica”. En Clavería, G. y M. Freixas (2018a). El diccionario de la Academia en el siglo XIX: la 5. ${ }^{a}$ edición (1817) al microscopio. Madrid: Arco/ Libros, pp. 399-426.

Martín Zorraquino, M. a A. (1997). "Formación de palabras y lenguaje técnico", Revista Española de Lingüística, 27, 2, pp. 317-339.

Muñoz Armijo, L. (2007). "La recepción de los derivados en -ismo e -ista en la lexicografía española no académica de la primera mitad del siglo XIX", Revista de Lexicografía, XIII, pp. 75-104.

Muñoz Armijo, L. (2010). La historia de los derivados en -ismo e -ista en el español moderno. Bellaterra: Universitat Autònoma de Barcelona. Tesis doctoral en TDX. ISBN: 9788469367148; Dipósito legal: B-16200-2011.

Muñoz Armijo, L. (2012). La historia de los sufijos -ismo e -ista: evolución morfológica y semántica en la tradición lexicográfica académica española. San Millán de la Cogolla: Cilengua.

Muñoz Armijo, L. (2015). "Relaciones formales y semánticas en el sistema derivativo para la formulación de sales y compuestos químicos en el español moderno". En Brumme, J. y C. L. Ferrero (eds.) (2015). La ciencia como diálogo entre teorias, textos y lenguas, Berlín: Frank \& Timme (Colección: Forum für Fachsprachen-Forschung), pp. 127-144. 
Núñez de Taboada, M. (1825). Diccionario de la lengua castellana para cuya composición se han consultado los mejores vocabularios de esta lengua, y el de la Real Academia Española últimamente publicado en 1822; aumentado con más de 5000 voces o artículos que no se hallan en ninguno de ellos. Paris: Seguin [consultado a partir del NTLLE].

Peñalver, J. (1842). Panléxico. Diccionario universal de la lengua castellana. Madrid: Imprenta de D. Ignacio Boix.

Raab, M. (2018). "La lexicografía no académica y la quinta edición del DRAE". En Clavería, G. y M. Freixas (2018): El diccionario de la Academia en el siglo XIX: la 5. ${ }^{a}$ edición (1817) al microscopio. Madrid: Arco/Libros, pp. 529- 542.

Reglas $(1838)=$ Real Academia Española: Reglas para la corrección y aumento del diccionario. Madrid: Imprenta Nacional.

Rodríguez, F. (1996). Introducción y desarrollo del léxico del ferrocarril en la lengua española. Barcelona: Universidad de Barcelona. [tesis doctoral: https://www.tesisenred.net/handle/10803/1715].

Rodríguez, F. y Garriga, C. (2010). "La teoría lexicográfica de la Academia en los siglos XVIII y XIX a través de las reglas", Quaderns de Filología. Estudis Lingüistics, 15, pp. 31-56.

Salas, R. de (1833). Prontuario de artillería para el servicio de campaña, por orden alfabético o de materias, segunda edición. Madrid: Oficina de E. Aguado.

Salvá, V. (1846). Nuevo diccionario de la lengua castellana, que comprende la última edición íntegra, muy rectificada y mejorada del publicado por la Academia Española [...]. París: Vicente Salvá [consultado a partir del NTLLE].

Terreros, E. (1786-1793). Diccionario castellano con las voces de ciencias y artes y sus correspondientes en las tres lenguas francesa, latina e italiana [...]. Madrid: Viuda de Ibarra [consultado a partir del NTLLE].

Terrón, N. (2019). "Historia de la lengua y lexicografía: el aumento de voces en la $6 .^{\text {a }}$ edición del Diccionario de la Academia (1822)")". En Arnal, M. ${ }^{a}$ L. et alii (eds.). Actas del X Congreso Internacional de Historia de la Lengua Española. Zaragoza: Institución "Fernando el Católico", vol. II, pp. 1325-1341.

Torruella J. y S. Huertas (2018). "Las voces de especialidad: caracterización general”. En Clavería, G. y M. Freixas (2018). El diccionario de la Academia en el siglo XIX: la 5. ${ }^{a}$ edición (1817) al microscopio. Madrid: Arco/Libros, pp. 253- 274. 